\title{
A CADEIA IMPERIALISTA DAS RELAÇÕES INTERESTATAIS: A TEORIA DO IMPERIALISMO DE NICOS POULANTZAS
}

\section{Caio Bugiato ${ }^{1}$}

\section{Resumo:}

Este artigo trata de teoria do imperialismo de Nicos Poulantzas contida em duas de suas principais obras: As classes sociais no capitalismo hoje e A crise das ditaduras: Grécia, Espanha e Portugal. Os trabalhos de Poulantzas são mais conhecidos pelas teses sobre o Estado capitalista, o bloco no poder e as classes e frações de classes sociais. Entretanto, é possível verificar que o autor construiu uma rica teoria que aborda as relações internacionais de forma complexa e baseada na luta de classes e que sua contribuição para o campo das Relações Internacionais, apesar de ser atualmente tímida, comporta enorme potencial.

Palavras-chave: Nicos Poulantzas. Imperialismo. Metrópoles imperialistas. Formações sociais dominadas e dependentes. Estado burguês. Bloco no poder. Frações burguesas.

\section{INTRODUÇÃO}

O texto a seguir é uma explanação sobre a teoria do imperialismo contida nos estudos de Nicos Poulantzas. $\mathrm{O}$ autor publicou em um intervalo de dez anos suas principais obras, revigorando e fortalecendo a teoria política marxista: Poder político e classes sociais em 1968, Fascismo e ditadura em 1970, As classes sociais no capitalismo hoje em 1974, A crise das ditaduras: Grécia, Espanha e Portugal em 1975 e O Estado, o poder, o socialismo em 1978. Neste texto extraímos a teoria do imperialismo de suas obras que abordam o tema, As classes sociais no capitalismo hoje, em que o autor em meio a uma série de teses e conceitos apresenta sua teoria do imperialismo, e A crise das ditaduras: Grécia, Espanha e Portugal, em que a operacionaliza, analisando a derrocada dos regimes ditatoriais nestes países ${ }^{2}$.

A construção da teoria do imperialismo de Poulantzas (1978) se inicia com a retomada de outras teorias sobre as relações internacionais entre Estados e burguesias no capitalismo do século XX, às quais defere uma série de críticas. Em primeiro lugar, Poulantzas critica um conjunto de autores, entre eles Paul Sweezy e Harry Magdoff,

\footnotetext{
${ }^{1}$ Professor do curso de Relações Internacionais da UNISANTOS. Pesquisador do Centro de Estudos Marxistas (CEMARX) da UNICAMP. Doutorando no programa de pós-graduação em Ciência Política na UNICAMP. E-mail: bugiato@live.com

${ }^{2}$ Alguns autores sustentam que existe uma periodização no pensamento de Poulantzas, pois ele teria passado da filiação ao pensamento do filósofo marxista Louis Althusser, pensamento presente em Poder Político e classes sociais, para o campo do socialismo-democrático, retificando alguns pressupostos teóricos ao longo de sua trajetória intelectual, concentrados em O Estado, o poder, o socialismo. Sobre tal periodização, ver CODATO, 2008.
} 
nomeados como partícipes da versão atualizada do ultra imperialismo de Karl Kautsky. Uma vez que subestimam as contradições interimperialistas baseadas no desenvolvimento desigual, isto é, apenas enxergam na cadeia imperialista a delimitação que separa metrópoles imperialistas e países dominados e identificam as relações das metrópoles entre si fundamentadas na pacificação e integração sob a dominação do capital estadunidense.

A segunda crítica está dirigida a duas teses que tem uma base comum, de que os Estados e burguesias são autônomos e independentes uns dos outros no plano internacional e o processo de internacionalização do capital atinge somente o nível da econômica. De um lado autores como Ernest Mandel, além de adotar a mesma e única delimitação da tese anterior, analisam as contradições interimperialistas como foram no passado: Estados e burguesias autônomos e independentes na luta pela hegemonia, desprezando a interdependência complexa entre eles, como se relacionassem apenas no plano externo, considerando na melhor das hipóteses conexões de mercado. Contudo, e de maneira contraditória, nessas relações internacionais a hegemonia se dá como no passado, com a construção de centros hegemônicos sobre impérios de países dominados e dependentes. Do outro lado, as análises dos partidos comunistas ocidentais, particularmente a do francês, em que a internacionalização do capital atinge apenas as forças produtivas, criando uma espécie de "capital cosmopolita" ou "capitais cosmopolitas". Assim, Estados e burguesias autônomos e independentes têm um acordo no nível econômico, sob a dominação do capital estadunidense, no qual os monopólios (cosmopolitas) são designados à busca de altas taxas de lucro. Para Poulantzas esses teóricos não conseguiram apreender as modificações da corrente imperialista, sobretudo as relações entre as metrópoles imperialistas. Vejamos então a teoria do autor.

\section{ESCLARECIMENTOS CONCEITUAIS}

Antes de abordar a teoria do imperialismo de Poulantzas, é necessário esclarecer os conceitos de formação social, classes sociais e luta de classes, Estado burguês e bloco no poder, os quais estão presentes nesta teoria. Por ora precisamos entender que formação social significa a existência concreta e simultânea de vários modos de produção em um dado local com predominância de algum deles. Formações sociais "são os lugares efetivos de existência e de reprodução dos modos e formas de produção", "comportam vários modos de produção, em uma articulação específica" e "estes modos de produção só existem e se reproduzem em formações sociais historicamente determinadas" (POULANTZAS, 1978, p. 23-24). E, assim, toda formação social, em sua base predominante, tem uma determinação última na esfera econômica. No caso de uma formação social capitalista, em linhas gerais, o que vigora são as relações de produção em que os trabalhadores, destituídos dos meios de produção e "livres" para negociar sua força de trabalho no mercado, tornam-se assalariados da burguesia, a qual em contrapartida aufere seus lucros da extorsão do sobretrabalho. 
Numa formação social onde o modo de produção capitalista é dominante (e em outros modos de produção também), as funções do Estado estão relacionadas aos níveis da economia, da ideologia e da política. No nível da economia, a função do sistema jurídico é, em geral, organizar o processo de produção, regulamentar contratos de compra e venda da força de trabalho e regular as trocas capitalistas. No nível ideológico, o Estado estabelece normas para os sistemas de educação, de comunicação e de informação no âmbito nacional. E no político, a função do Estado consiste na manutenção da ordem política no conflito entre as classes. Essas funções não podem ser apreendidas se não estiverem inseridas no papel político global do Estado: a manutenção da unidade de uma formação social no interior da qual se dá a dominação de alguma(s) classe(s) sobre outra(s). Dessa forma, as funções do Estado na economia e no plano ideológico não são técnicas e/ou neutras, mas sim constituem funções políticas na medida em que visam à manutenção da unidade da formação social.

Em toda formação social está presente a luta de classes, luta esta que fundamentalmente opõe burguesia e proletariado. Para Poulantzas, "classes sociais são conjunto de agentes sociais determinados principalmente, mas não exclusivamente, por seu lugar no processo de produção, isto é, na esfera econômica" (POULANTZAS, 1978 p. 13-14,). As classes sociais significam conflito, dado que cada uma delas persegue seus interesses específicos, contrários (mas nem sempre) aos interesses de outras classes. Uma classe social se define pelo seu conjunto nas práticas sociais, ou seja, pelo seu lugar no processo de produção, pelas ações políticas que toma e pela sua posição ideológica. Isso quer dizer que um conjunto de agentes sociais se estabelece como classe social na medida em que sua unidade atravessa as esferas econômica, política e ideológica.

Tais conceitos são necessários para podermos entender o Estado em geral. O Estado é fator de coesão de uma formação social atravessada pela luta de classes. O Estado é o fator da ordem e regulador do equilíbrio global do sistema, cuja finalidade é a manutenção da unidade de uma formação social, seu funcionamento e sua reprodução. Nele refletem as contradições da formação social, que é o antagonismo entre as classes sociais. $\mathrm{O}$ Estado, em última instância, impede que se aniquilem as classes sociais, o que significa dizer que impede a destruição de uma formação social (POULANTZAS, 1977). Assim sendo, a definição de Estado burguês (ou capitalista) está alicerçada em um tipo de Estado que organiza um modo particular de dominação de classe e em um Estado que corresponde 3 às relações de produção capitalistas (SAES, 1985). Vejamos.

O Estado burguês, núcleo da estrutura jurídico-política do modo de produção capitalista, conceitualmente é um sistema articulado de quatro elementos: o direito burguês (ou capitalista), o burocratismo,

\footnotetext{
${ }^{3} \mathrm{O}$ termo correspondência está em oposição ao modo economicista e mecanicista que considera a formação e a organização do Estado capitalista como reflexo da dominância das relações de produção capitalistas numa formação social. A correspondência não consiste numa relação causal unívoca. Um tipo particular de Estado corresponde a um tipo particular de relações de produção "na medida em que só uma estrutura jurídico-política específica torna possível a reprodução das relações de produção” (SAES, 1985, p. 26). Apenas o Estado burguês torna possível a reprodução das relações de produção capitalistas (SAES, 1985).
} 
o efeito isolamento e o efeito unidade de representação. $\mathrm{O}$ direito burguês ${ }^{4}$, valores jurídicos que regulam e enquadram as práticas econômicas e relações sociais por ele condicionadas, consiste em atribuir a todos os agentes da produção, independente do lugar que ocupam no processo de produção, a condição de sujeitos individuais "livres" e "iguais", capazes de praticar atos de vontade legitimamente. O burocratismo ${ }^{5}$ (valores burocráticos) determina que a) todos os agente de produção, independente do lugar que ocupam no processo produtivo, tenham formalmente acesso às práticas que regulam e enquadram as práticas econômicas e relações sociais por ele condicionadas (acesso universal à burocracia de Estado) e que b) os agentes de tais práticas sejam hierarquizados, de modo que esse escalonamento não apareça como subordinação, mas formalmente como gradação de competências individuais exigidas pelas diferentes tarefas dessa atividade social (SAES, 1998).

Os valores burocráticos capitalistas constituem a expressão e o desdobramento, num plano mais restrito, dos valores jurídicos capitalistas; um é condição de existência do outro, formando uma unidade. Se por um lado os agentes de produção são definidos pelo direito como indivíduos "livres" e "iguais", todos eles têm o direito de pleitear o desempenho das práticas do burocratismo. Por outro, a hierarquização dos agentes encarregados de exercer as práticas do burocratismo (não proibição do acesso a essas tarefas a membros da classe explorada) se formaliza mediante o critério de competência individual para o desempenho das tarefas. Esses elementos permitem conceitualmente a unidade da estrutura político-jurídica capitalistas (SAES, 1998).

Segundo Poulantzas (1977) essa estrutura político-jurídica produz efeitos político-ideológicos nos agentes da produção: efeito isolamento e o efeito representação da unidade. Os valores jurídicos capitalistas se conjugam com a estrutura econômica (a qual atomiza o coletivo dos produtores diretos) produzindo o efeito isolamento ou individualização. Este consiste na reprodução regular das relações de produção capitalista por a) suscitar a prática econômica de buscar por vontade própria (e não por coerção extra econômica) a venda individualizada da força de trabalho ao um proprietário individual dos meios de produção e por b) impedir a emergência de uma prática política mediante a qual os trabalhadores se posicionassem de forma coletiva diante do

\footnotetext{
${ }^{4}$ Podemos considerar o direito como "conjunto de regras (escritas ou não) que disciplinam e regularizam as relações entre os agentes da produção [...] de modo a possibilitar a sua reiteração" (SAES, 1985, p. 36) e que "instaura igualmente a previsibilidade nas relações entre os agentes e, portanto, criam também a possibilidade de repetição” (SAES, 1985, p.36). Saes (1985) elenca os componentes do direto burguês: a lei, sistema de normas que se impõe aos agentes de produção - constituição, códigos, etc., e o processo de aplicação da lei, concretização do seu caráter impositivo. Ambos fazem parte de uma organização material e humana, o poder judiciário, que cria a condições para a reprodução das relações de produção capitalistas.

${ }^{5} \mathrm{O}$ burocratismo burguês é o modo particular de organização do conjunto de recursos materiais e humanos do tipo burguês de Estado. Os elementos desse conjunto são as forças armadas e as forças coletoras (agentes que arrecadam diversos tributos destinados à manutenção e ao funcionamento do Estado). Dessa forma, o burocratismo burguês é o modo particular por meio do qual o Estado burguês organiza as forças armadas e as forças coletoras. Ela não se restringe apenas às forças armadas e coletoras, abrange outros ramos do aparelho de Estado como a administração e o judiciário. Segundo Saes (1985) o burocratismo deriva de duas normas fundamentais: a) "a não monopolização das tarefas do Estado - forças armadas e forças coletoras - pela classe exploradora ou não proibição do acesso a essas tarefas a membros da classe explorada" (SAES, 1985, p.39) e b) "hierarquização das tarefas do Estado segundo o critério da competência, isto é, do nível de conhecimento ou saber exigido aos que se dispõem a desempenhá-las" (SAES, 1985, p.39).
} 
proprietário dos meios de produção. Os valores burocráticos, ao converterem os agentes encarregados de regular enquadrar as práticas econômicas e relações sociais por eles condicionados numa burocracia "universalista" e "competente", permitem que tal grupo unifique ideologicamente todos os agentes, já individualizados pelo efeito isolamento, por meio da constituição de uma comunidade simbólica: o "povo nação", composto por todos os agentes da produção inseridos num determinado território. Este processo, articulado ao efeito isolamento, é qualificado como o efeito de representação da unidade. O qual contribui para a reprodução das relações de produção capitalistas na medida em que frustra a constituição de grupos sociais antagônicos (classes sociais), ao reuni-los no "povo-nação", representados num Estado de suposto acesso universal, o Estado-nação.

A tradição marxista se vale da afirmação de Marx e Engles, no Manifesto do Partido Comunista, segundo a qual o Estado moderno não é senão o comitê executivo dos negócios comuns de toda a classe burguesa, para conceber o Estado burguês como a representação da dominação de classe. Cabe aqui, então, uma indagação: se o Estado tende a isolar as pessoas como indivíduos e reunificá-los como "povo nação", como consegue a burguesia (que também sofrem os efeitos de isolamento e de unidade) apoderar-se do Estado para realizar seus interesses e se tornar a classe dominante? Segundo Poulantzas, a função do Estado como mantenedor da unidade de uma formação social capitalista é o objetivo de fundo da burguesia: manutenção das relações sociais existentes e, para concretizá-lo, a conservação do Estado é imprescindível. Essa prática da burguesia de conservação das relações sociais é o que dá unidade à classe e aliada a sua operação ideológica, que "consiste no fato de tentar impor, ao conjunto da sociedade, um 'modo de vida' através do qual o Estado será vivido como representante do 'interesse geral' da sociedade, como detentor das chaves do universal, em face de 'indivíduos privados"' (POULANTAZAS, 1977, p. 209), constitui-a como força social. O Estado burguês "representa não diretamente os interesses econômicos das classes dominantes, mas os seus interesses políticos: ele é o centro de poder político das classes dominantes na medida em que é o fator de organização da sua luta política" (POULANTZAS, 1977, p. 185). Garantir a dominação de classe faz parte da função do Estado, pois o Estado como instituição não possui poder próprio. Vale salientar que poder, para Poulantzas é a capacidade de uma classe social ou fração realizar seus interesses específicos.

A complexa relação entre a classe dominante e suas frações e o Estado burguês são elucidadas por meio do conceito de bloco no poder. O bloco no poder é a unidade contraditória das frações da classe burguesa em torno de objetivos gerais - referentes à manutenção das relações de produção capitalistas -, unidade essa que não elimina os objetivos particulares de cada fração. O bloco no poder não é um acordo político explícito, mas uma comunidade de interesses dos proprietários dos meios sociais de produção. Sua unidade é garantida pelo interesse comum às frações de governar direta ou indiretamente o Estado, fazendo com que este atenda seus interesses gerais (a manutenção da propriedade privada dos meios de produção e a reprodução da força de trabalho como 
mercadoria) e específicos de cada fração. O Estado é, portanto, fator de unidade política do bloco no poder (POULANTZAS, 1977).

$\mathrm{Na}$ articulação do bloco no poder há a tendência à formação de um núcleo hegemônico, composto por uma (ou mais) fração, a fração hegemônica. A hegemonia é conquistada por meio da capacidade de uma fração fazer prevalecer os seus interesses particulares no interior do bloco no poder, ou seja, é a capacidade da fração de obter a prioridade dos benefícios, principalmente, da política econômica do Estado (isto é, outras políticas estatais, com a social e a externa também são relevantes) ${ }^{6}$. As políticas estatais (sobretudo a política econômica) provoca a constituição das frações e ao mesmo tempo indica a posição delas no interior do bloco. A relação entre o Estado burguês e as frações se dá no sentido da sua unidade política sob a égide de uma (ou mais) fração hegemônica? Como já dissemos, é a classe ou fração que detém o poder, o Estado não possui poder próprio.

\section{A TEORIA DO IMPERIALISMO}

Uma vez conhecidos tais conceitos, já possuímos elementos suficientes para entender como Poulantzas trata de relações entre os Estados (burgueses). Para Poulantzas (1978) o modo de produção capitalista (MPC) é caracterizado pela dupla tendência concomitante da reprodução numa formação social, onde se consolida e domina outros modos de produção, e da extensão para o exterior. Esta segunda, originada pela tendência decrescente da taxa de lucro, é marcada predominantemente pela exportação de capitais em relação à exportação de mercadorias. A essa tendência ao exterior do capital em que predomina a exportação de capitais, cujo destino é a exploração de outras formações sociais, Poulantzas - concordando com Vladimir Lenin - chama de imperialismo. A corrente imperialista, conjunto de formações sociais em que prevalece o modo de produção capitalista, padece de um desenvolvimento desigual das forças produtivas e relações de produção. Isso quer dizer que países diversos possuem em seu território diferentes "graus" de desenvolvimento do modo de produção capitalista, resultando numa delimitação da corrente entre metrópoles imperialistas - centros autóctones de

\footnotetext{
${ }^{6}$ Duas observações esclarecedoras. Primeira, a preponderância econômica de uma fração sobre as demais não é indicador de hegemonia. Isto é, não é a maior participação nos lucros da mais-valia global que determina a hegemonia. A política econômica deve ser critério privilegiado para detectar a hegemonia no interior do bloco no poder. O processo de formulação de uma política econômica significa que interesses particulares de uma fração são atendidos em detrimento de outras. Assim, tal processo é um campo de luta onde se decide questões de interesses de classe e sua resultante reflete as relações de força entre as frações dominantes (PERISSINOTTO, 1994). Segunda, uma fração de classe que não é preponderante na esfera econômica pode conquistar a hegemonia política, o que serve para alavancar sua nova preponderância econômica. Contudo, no médio e longo prazo, a tendência é a correspondência entre hegemonia política e preponderância econômica. "É quando uma política antecipadora da preponderância econômica se transforma numa política de adaptação a essa prevalência (FARIAS, 2010, p. 31).

${ }^{7}$ Para Poulantzas, a hegemonia possui dois campos de atuação: no interior do bloco no poder entre as frações da burguesia e do bloco no poder para as classes dominadas, processo analisado por Antonio Gramsci no qual o modo de vida e os interesses da classe dominante se enraízam no pensamento das classes dominadas.
} 
acumulação de capital/ "capitalismo avançado" - e formações sociais dominadas e dependentes (FSDD) processo de acumulação dependente do exterior/ "capitalismo atrasado".

O imperialismo, de acordo com o autor, pode ser distinguido em fases. Primeira, a transição do capitalismo competitivo para capitalismo monopolista, que vai do fim do século XIX até o período entre guerras, em que nas metrópoles se formam os monopólios e ocorre um equilibrio entre a forma de exportação de mercadorias e a forma de exportação de capital. Segundo, a fase de consolidação do estágio imperialista (após a crise de 1929), em que nas metrópoles o capitalismo monopolista domina o capitalismo competitivo. Nestas duas fases, as FSDD passaram das simples condições de tipo colonial e de tipo capitalista-comercial (exportação de produtos agrícolas) para condições em que ocorre a dominância do MPC, em "graus" desiguais e obviamente retrasados em relação às metrópoles. A dominância do MPC não extinguiu os outros modos e formas de produção, mas progressivamente eliminou a antiga dicotomia metrópole/cidade/indústria X formações dominadas/campo/agricultura, dando origem ao chamado subdesenvolvimento ou industrialização periférica.

Não se trata mais de formações sociais de relações relativamente externas. $\mathrm{O}$ processo de dominação e dependência imperialista aparece agora em diante como a reprodução, no próprio seio das formações sociais dominadas e sob formas especificas para cada uma delas, da relação de dominação que a liga às metrópoles imperialistas (Poulantzas, 1978, p. 46). ${ }^{8}$

Durante estas duas fases, quanto à relação das metrópoles imperialistas entre si, as contradições interimperialistas provocam a predominância alternada de uma metrópole sobre a outra (Grã-Bretanha, Estados Unidos, Alemanha), predominância esta que é fundamentada na dominação e na exploração que cada metrópole impõe ao seu "império" de FSDD" e no ritmo de desenvolvimento capitalista no interior da própria metrópole. Terceira, após o fim da Segunda Guerra Mundial, é o que Poulantzas chama de fase atual, que conserva as características da fase de consolidação, enfatizando o domínio do MPC nas FSDD não simplesmente do exterior, mas sim pela dominância no interior destas, onde o modo de produção das metrópoles se reproduz de forma específica. Reprodução que provoca nessas formações o alojamento de capitais em formas de indústria leve e de tecnologia inferior, a exploração da força de trabalho através principalmente de baixos salários - mantendo sua baixa qualificação -, reservando o trabalho qualificado para os países centrais, a existência de setores isolados com altas concentrações de capital e produtividade do trabalho e elevado grau de expatriação dos lucros (Poulantzas,

\footnotetext{
${ }^{8}$ Segue Poulantzas: "Uma formação social é dominada e dependente quando a articulação da sua própria estrutura econômica, política e ideológica exprime relações constitutivas e assimétricas, com uma ou várias formações sociais que ocupam, em relação a primeira, uma situação de poder" (POULANTZAS, 1978, p. 47). Uma questão apenas citada pelo autor é que tais relações assimétricas repercutem nas relações de classe e no aparelho de Estado da formação dominada, reproduzindo as formas de dominação a(s) classe(s) no poder na formação social dominante. Ou seja, essas formas de dominação correspondem a formas de exploração das massas populares de maneira indireta (quando a burguesia estrangeira explora por intermédio da burguesia local) ou direta (quando a burguesia estrangeira explora diretamente os trabalhadores locais). Questão semelhante levantou Ruy Mauro Marini, quando trata em seus estudos, dentre eles Dialética da dependência (1973), da superexploração do trabalho nos países dependentes da América Latina.

${ }^{9}$ Gerson Moura no seu livro Autonomia na dependência (1980) se refere a tais impérios como sistemas de poder.
} 
1976). Processo este que o autor denomina de reprodução interiorizada e induzida, que afeta as relações econômicas, políticas (inclusive os aparelhos de Estado) e ideológicas.

Esse desenvolvimento desigual não constitui para Poulantzas um resquício de impureza no MPC devido a sua combinação com outros modos de produção: ele é a forma constitutiva da reprodução do capitalismo em escala mundial no estágio imperialista, nas suas relações com outras formações sociais que contem outros modos de produção. Essa internacionalização do MPC, ou sua fase atual para o autor, tendendo a abarcar todos os rincões do mundo não é uma integração das formações sociais, mas a reprodução interiorizada e induzida do MPC das metrópoles nas FSDD.

A fase atual (POULANTZAS) da divisão internacional do trabalho - metrópoles imperialistas X FSDD - introduz outra, e nova, linha de demarcação. Uma demarcação no campo interimperialista: de um lado a metrópole hegemônica, os Estados Unidos, e de outro as metrópoles imperialistas da Europa. A relação entre ambos é marcada pelo predomínio do capital monopolista estadunidense e sua reprodução interiorizada e induzida no interior das outras metrópoles, reproduzindo igualmente condições políticas e ideológicas do imperialismo estadunidense. Essa relação de dependência, contudo, não se identifica com aquela entre metrópoles e FSDD, pois as metrópoles continuam a constituir centros autóctones de acumulação de capital.

Poulantzas (1978) identifica elementos dessa nova demarcação sob a hegemonia dos capitais estadunidenses, modificada pela tendência decrescente da taxa de lucro. 1) O crescimento do volume global de investimentos dos EUA no pós-guerra, criando um hiato entre este país e as outras metrópoles. 2) O destino privilegiado dos capitais estadunidenses não são mais as formações periféricas, mas as metrópoles europeias. 3) Estes investimentos são majoritariamente diretos (em capital fixo e/ou que tendem à tomada de controle de empresas) em detrimento do investimento em carteira (compra de operações financeiras/em bolsa de valores de curto prazo) e, em comparação com as formações periféricas, o reinvestimento dos lucros na região é significativamente maior. 4) A maior parte dos investimentos estadunidenses na Europa é na indústria de transformação (capital produtivo) em detrimento da indústria extrativa (matérias-primas) e dos setores de serviço e comércio, enquanto que os investimentos diretos europeus nos EUA são em sua maioria no setor de serviços. 5) Os investimentos estadunidenses na Europa provem de ramos de alta concentração e centralização de capital (monopólio) e se dirigem para ramos de forte concentração - o capital produtivo estadunidense impõe a concentração do capital produtivo europeu; os ramos investidos são aqueles que apresentam tecnologia mais avançada e rápida expansão, isto é, apresentam alta produtividade e exploração intensiva do trabalho pela alta composição orgânica de capital ${ }^{10}$.6) A exportação de capitais estadunidenses para a Europa compreende também

\footnotetext{
${ }^{10}$ A mudança dos investimentos estadunidenses para a Europa é explicada por Poulantzas por um processo de deslocamento de exploração. "Este deslocamento é ele próprio função do caráter principal da concentração monopolista: a alta da composição vol.07, nº. 02, Rio de Janeiro, 2014. pp. 453-468 
a concentração do capital-dinheiro, grandes bancos e holdings financeiras, o que não significa que a acumulação de capital e a taxa de lucro destes seja determinada pela valorização D - D', mas sim que acompanham os investimentos no ciclo do capital produtivo ${ }^{11}$. Todos esses elementos convergem para um objetivo: alta taxa de exploração com a finalidade de contrabalancear a tendência decrescente da taxa de lucro. É aí que reside o motivo da reprodução induzida e interiorizada do capital monopolista em formações sociais exteriores.

Em suma, atual fase do imperialismo para Poulantzas é composta pelo processo de internacionalização do capital descrito acima (em que os EUA não são os únicos exportadores de capital) e pela socialização internacional dos processos de trabalho, que em geral significa, nas palavras do autor, "a constituição sob propriedade única, de efetivas unidades de produção complexas a processos de trabalho estreitamente articulados e integrados [...] cujos diversos estabelecimentos se distribuem em vários países”. A síntese empírica desses elementos são as empresas multinacionais industriais, que, além de dominar a produção, dominam as trocas internacionais, uma vez que o comércio entre unidades (localizadas especialmente nas metrópoles) respondem por uma alta porcentagem do comercio mundial.

Antes de entrar nas relações políticas do imperialismo (pois até agora abordamos basicamente as relações econômicas), é necessário reafirmar, então, que a divisão internacional do trabalho da cadeia imperialista possui duas dinâmicas (imbricadas): de um lado as relações imperialistas metrópoles-FSDD e de outro as relações metrópole-metrópoles. Cada uma apresenta uma forma distinta de exploração: enquanto a exploração das massas populares nas FSDD pela classe dominante da metrópole se dá prioritariamente de forma indireta por intermédio da classe dominante local - e secundariamente de forma direta - capital estrangeiro diretamente investido no seu interior -, na relação metrópole-metrópoles a forma direta é a principal e a indireta secundária ${ }^{12}$ (POULANTZAS, 1978). Portanto, podemos dizer que para Poulantzas existe um sistema internacional de Estados burgueses divididos em metrópoles e FSDD, em que o imperialismo é a relação (o capital é antes de tudo uma relação social, como demonstra Marx n’ O Capital) que se dá muitas vezes (mas nem sempre) entre eles,

orgânica do capital, isto é, o aumento da capital constante em relação ao capital variável (custos salariais), e a diminuição do trabalho vivo em relação ao 'trabalho morto' (incorporado nos meios de trabalho). Esta alta composição orgânica do capital sendo inversamente proporcional à taxa de lucro, é onde se inscreve a tendência atual para as inovações tecnológicas. Mas o trabalho permanece sempre a base da mais-valia: é o que explica a tendência atual para um aumento da taxa de exploração pelo desvio principal de uma exploração intensiva do trabalho, diretamente ligada a produtividade do trabalhado (mais-valia relativa)" (POULANTZAS, 1978, p. 68).

${ }^{11}$ Poulantzas diferencia o capital bancário, o capital na forma dinheiro, que corresponde a uma etapa do processo de produção em que atuam principalmente os bancos e pode se tornar uma fração de classe, do capital financeiro, que não é uma fração do capital como os outros, mas um processo junção e o modo de funcionamento de vários capitais reunidos em busca de valorização.

${ }^{12}$ Um exemplo que clarifica tais relações pode ser encontrado na industrialização dependente. Neste processo, a burguesia periférica adquire máquinas e equipamentos (ultrapassados para os países centrais) do exterior, precisando, além da alta taxa de lucro, pagar juros e amortizações. Daí a alta intensidade de exploração do trabalho, que está relacionada com a exploração da burguesia local e a condição de dependência às burguesias centrais. No caso da relação metrópole-metrópole, o capital estrangeiro está presente no interior da formação social, explorando diretamente os trabalhadores. 
mediante a reprodução interiorizada e induzida do MPC. O imperialismo "nada tem de amigável", para usar as palavras do autor, ele é uma relação de força em que o Estado cumpre papel decisivo. Passemos a elas.

Uma vez definidos os conceitos de Estado burguês, classes sociais e bloco no poder, tratemos da burguesia. A burguesia é uma classe dotada de complexa heterogeneidade. Suas clivagens econômicas se dão pelo ciclo de reprodução do capital (capital comercial, industrial, bancário, etc.), pela concentração e centralização do capital (grande e médio e monopolista e não monopolista), pelas relações com o imperialismo (burguesia nacional, interna e compradora), dentre outros aspectos, bem como as dimensões políticas e ideológicas que podem gerar a formação de determinada fração de classe. Essas clivagens se podem combinar de maneiras variadas e dinâmicas e como base da aglutinação ou divisão política das frações. Se tais clivagens propiciam ou não a formação de frações burguesas depende das circunstâncias e da reação desses setores da burguesia frente principalmente à política econômica do Estado.

Interessam-nos particularmente nesse texto as relações da burguesia com o imperialismo. Segundo Poulantzas (1976 e 1978) se distinguem as frações dessa classe em burguesia compradora, burguesia nacional e burguesia interna. A burguesia compradora é a fração cujos interesses estão diretamente subordinados aos do capital estrangeiro e que serve de intermediária direta para a implantação e reprodução do capital estrangeiro no interior duma formação social. As ingerências do capital externo "só podem, em geral, exercer um papel decisivo nos diversos países dependentes [...] articulando-se, nestes países, às relações de força internas" (POULANTZAS,1976, p 20. Grifos do autor). Esta fração não tem base de acumulação própria e geralmente tem sua atividade ligada ao latifúndio (FSDD) e à especulação, concentrada em setores financeiros, bancários e comerciais, mas igualmente podendo atuar nos ramos industriais, naqueles inteiramente subordinados e dependentes ao capital estrangeiro. Do ponto de vista político-ideológico, é suporte e agente do capital imperialista. A burguesia nacional é fração autóctone, que possui base de acumulação própria no interior da formação social e apresenta autonomia política-ideológica frente ao capital imperialista. Em determinadas conjunturas, em aliança com as classes dominadas, esta fração pode adotar uma postura anti-imperialista e/ou se envolver em uma luta de libertação nacional. A burguesia interna ocupa uma posição intermediária entre a burguesia compradora e a burguesia nacional, apresentando contradições com o capital estrangeiro. Possui base de acumulação própria, tentando assim limitar a presença do capital estrangeiro no mercado interno, porém ao mesmo tempo é dependente desse capital em áreas como investimento e tecnologia ${ }^{13}$.

A burguesia interna, ao contrário, mesmo sendo dependente do capital estrangeiro, apresenta contradições em relação a este. Em primeiro lugar porque se sente frustrada na repartição do bolo da exploração das massas: a transferência leonina da mais-valia se faz em detrimento dela e a favor do capital estrangeiro e respectivos agentes, a burguesia

\footnotetext{
${ }^{13}$ Poulantzas formula o conceito de burguesia interna, pois de acordo com ele a antiga dicotomia burguesia nacional X burguesia compradora não explica o movimento das frações burguesas na atual fase do imperialismo.
} 
compradora. Em seguida porque, concentrada principalmente no setor industrial, se interessa pelo desenvolvimento industrial que esteja menos polarizado para o seccionamento do país causado pelo capital estrangeiro e se interessa pela intervenção estatal que the assegura alguns domínios dentro do país e que a tornaria também mais competitiva diante de capital estrangeiro. Deseja a ampliação e o desenvolvimento do mercado interno através de uma pequena elevação do poder de compra e de consumo das massas, o que the ofereceria mais saídas; procura, enfim, ajuda do Estado, que the permitiria desenvolver a exportação (POULANTZAS, 1976, p. 36-37)

O surgimento dessa fração está ligado à reprodução induzida e interiorizada das relações capitalistas nas diversas formações sociais - tanto periféricas quanto centrais -, sendo dependente dos processos de internacionalização do capital sob a égide do capital estrangeiro. Tal dependência, entre outros fatores, explica sua fraqueza político-ideológica e sua consequente impossibilidade de exercer a hegemonia de longo prazo sobre o bloco no poder.

Rejeitando as teses sobre o processo de supressão que os Estados nacionais estariam sofrendo ${ }^{14}$, Poulantzas (1978) afirma que são os Estados, centrais e periféricos, que se encarregam dos interesses do capital (por meio de subsídios públicos, dispensas fiscais, política industrial favorável a determinados interesses, etc.) seja na relação metrópole-metrópoles, seja na relação metrópoles-FSDD. O Estado nacional intervém na luta entre as classes e frações de classe, organizando a hegemonia e a hierarquia no bloco no poder. Destarte, o bloco no poder não pode ser apreendido num plano puramente nacional, mas sim em um sistema internacional complexo de Estados burgueses em que cada Estado se encarrega dos interesses dos capitais "nacionais" e estrangeiros numa formação social, organizando a correlação de forças intraburguesa e constituindo uma determinada configuração no bloco no poder. Nesta configuração fração hegemônica tem seus interesses prioritariamente atendidos pelas políticas estatais em detrimento de outras frações. O Estado é concomitantemente arena e ator, e não um instrumento manipulável à vontade da classe dominante: é uma arena de luta entre as frações da burguesia, na qual uma (ou um conjunto) delas assuma a condição de hegemônica; dessa forma, em suas relações exteriores, o Estado é um ator na política internacional e na reprodução universal do capital que representa prioritariamente os interesses da fração hegemônica do seu bloco no poder ${ }^{15}$.

\footnotetext{
${ }^{14}$ Sobre esse debate, ver BUGIATO, 2011.

${ }^{15}$ Poulantzas comenta brevemente sobre as condições ideológicas (ideias, práticas, hábitos, modos, rituais) da reprodução induzida e interiorizada do imperialismo, dizendo que a extensão das formas ideológicas metropolitanas nas FSDD tem como característica principal uma desarticulação profunda de "setores ideológicos originários", provocando uma falsa imagem duma sociedade dualista (avançado X atrasado). Enquanto nas metrópoles não hegemônicas, tal extensão tem efeito sobre práticas e modos relativos à produção (know-how), criando-se uma imagem de atraso apenas econômico (POULANTZAS, 1978). O autor igualmente faz rápidos comentários sobre o problema que o desenvolvimento desigual dos países da cadeia imperialistas acarreta, como êxodo rural, concentração urbana, desemprego e marginalidade e tensões sociais acirradas pela imigração (POULANTZAS, 1976).
} 


\section{CONSIDERAÇÕES FINAIS}

Do ponto de vista histórico a teoria do imperialismo de Poulantzas possui um alto poder explicativo sobre o desenvolvimento do capitalismo no pós-guerra. Quanto às relações entre as metrópoles, o autor identifica a consolidação dos Estados Unidos como Estado hegemônico no mundo capitalista e esclarece que as relações deste com os Estado europeus não foram nada amigáveis no que se refere às classes e as frações de classe dominantes. O papel que os capitais estadunidenses desempenharam na reconstrução da Europa cumpriu funções essenciais para os Estados e as burguesias do velho continente, como o desenvolvimento e a dinamização da acumulação do capital - construindo o eixo dinâmico da acumulação capitalista mundial no pós-guerra (EUAEuropa) - e a preservação dos europeus no mundo capitalista, dada a polarização da Guerra Fria, entretanto gerando atritos entre as frações de classe mais e menos propensas a aceitar a ingerência dos interesses do capital estrangeiro. Quanto às relações entre metrópoles e FSDD, países periféricos como os da América Latina barganharam seus processos de industrialização com o capital imperialista, conservando as relações de dependência (não no mesmo formato) estabelecidas desde a colônia. No caso do Brasil, após 1930, os governos negociaram a industrialização nacional principalmente com o capital estadunidense, que no pós-guerra estava interessado em seus objetivos econômicos e estratégico-militares na Europa. No chamado período desenvolvimentista (1930-1985) a grande burguesia brasileira se dividiu basicamente em "entreguistas", aqueles que reivindicavam ampla participação do capital imperialista na industrialização nacional, e "nacionalistas", aqueles que defendiam um desenvolvimento mais autônomo do capitalismo brasileiro. De fato a grande burguesia brasileira nunca foi nacional (nos termos de Poulantzas), dado que a economia brasileira já nasceu subordinada ao mercado externo e seu processo de modernização sempre foi associado ao imperialismo, nas suas distintas fases. O que esteve em jogo no Brasil foi o grau dessa associação, jogo disputado na linha de frente entre a burguesia compradora e a burguesia interna.

Na teoria do imperialismo, Poulantzas antecipa um debate que emerge na década de 1990. A chamada globalização levou intelectuais de distintos matizes teóricos a decretar o declínio ou o fim do Estado nacional, pois a soberania e a autoridade deste seriam vítimas do triunfo irreversível do mercado global; pessoas, mercadorias, investimentos, serviços, conhecimento, tecnologia, informação circulariam livremente numa economia mundial sem fronteiras, destruindo as formas e funções tradicionais do Estado. Poulantzas (1976 e 1978), analisando a internacionalização do capital da década de 1970, constata que este processo não suprime e não abala os Estados nacionais nem no sentido de triunfo do mercado global nem no sentido de formação de um Estado supranacional sobre os escombros das velhas instituições. Ao contrário, os Estados são os nós do processo de internacionalização e alvos privilegiados das lutas entre as frações da burguesia. Pois são responsáveis por incorporar ou rechaçar os interesses do capital imperialista no interior da formação social, assim como se 
encarregam de representar os interesses do bloco no poder no plano internacional. É o Estado, estrutura jurídicopolítica, que celebra acordos e tratados internacionais, permite a exportação de capitais e mercadorias, define taxas de câmbio, juros, tarifas aduaneiras e a política protecionista em geral, resolve controvérsias comerciais em organizações internacionais, entre outras prerrogativas.

Por fim, a contribuição de Poulantzas para o estudo das Relações Internacionais é expressiva. Fred Halliday, em Repensando as Relações Internacionais (2002) escreveu que aqueles não querem falar sobre o capitalismo, não deveriam debater as relações internacionais; e que o imperialismo (marxista) raramente teve espaço nessa área. Poulantzas coloca o capitalismo como estrutura central na análise do sistema internacional e o imperialismo como conceito fundamental para entender as relações internacionais. Ademais, seu instrumental teórico contribui para alternativas no estudo das relações internacionais, dado que destoa das teorias dominantes no campo (que raramente tocam na problemática do capitalismo e do imperialismo), fornece uma teoria mais complexa relacionada à interação entre classes sociais, Estado e política internacional e permanece pertinente à realidade atual e sua transformação ${ }^{16}$. "É evidente que a dependência de um país em relação ao imperialismo só pode ser rompida por um processo de libertação nacional [...] que abranja um processo de transição ao socialismo" (POULANTZAS, 1976, p. 18).

\title{
THE IMPERIALIST CHAIN OF THE INTERSTATE RELATIONS: THE THEORY OF IMPERIALISM BY NICOS POULANTZAS
}

\begin{abstract}
:
This paper approaches the theory of imperialism by Nicos Poulantzas contained in two of his main titles: Classes in contemporary capitalism and The crisis of the dictatorships: Portugal, Greece, Spain. The works of Poulantzas are most frequently known by his thesis about capitalist state, power bloc and classes and fractions of social classes. However it is possible to verify that the author developed a rich theory that discusses in a complex way the international relations, founded on the class struggle, and that his contributions to the field of International Relations, despite of its current shyness, demonstrates enormous potential.
\end{abstract}

Keywords: Nicos Poulantzas. Imperialism. Imperialist metropoles. Dominated and dependent social formations. Bouegeois state. Power bloc. Bourgeois fractions.

\section{REFERÊNCIAS BIBLIOGRÁFICAS}

BOITO JR, Armando. Estado, política e classes sociais. São Paulo: Editora Unesp, 2007.

\footnotetext{
${ }^{16}$ Sobre a contribuição de Poulantzas para a Teoria de Relações Internacionais, ver BUGIATO e HERNANDEZ, 2011.
} vol.07, no. 02, Rio de Janeiro, 2014.pp. 453-468 
BUGIATO, Caio e HERNANDEZ, Matheus de Carvalho. Marxismo, Poulantzas e suas contribuições para o campo de Relações Internacionais. In: Revista de Estudos Internacionais, v.2, n.2. Universidade Estadual da Paraíba, 2011.

BUGIATO, Caio. Declínio do Estado-nação?. Dissertação (mestrado em Ciência Política). Unicamp. Campinas, 2011

CODATO, Adriano. Poulantzas, o Estado e a revolução. In: Revista Crítica Marxista. São Paulo: Editora Unesp, v. 27, p. $65-85,2008$.

FARIAS, Francisco. Estado e classes dominantes no Brasil (1930-1964). Tese (doutorado em Ciência Política), Unicamp, Campinas, 2010.

HALLIDAY, Fred. Repensando as Relações Internacionais. Porto Alegre: UFRGS, 2001.

LENIN, Vladimir. O imperialismo: fase superior do capitalismo. São Paulo, SP: Global, 1991,

MARINI, Ruy Mauro. Dialectica dela dependencia. México, DF: Era, 1973.

MOURA, Gerson. Autonomia na dependência. Rio de Janeiro: Nova Fronteira, 1980.

PERISSINOTO, Renato. Classes dominantes e hegemonia na República Velha. 1. ed. Campinas: Editora da Unicamp, 1994.

POULANTZAS, Nicos. A crise das ditaduras. Rio de Janeiro: Paz e Terra, 1976.

As classes sociais no capitalismo de hoje. Rio de Janeiro: Zahar, 1978.

Poder político e classes sociais. São Paulo: Martins Fontes, 1977.

SAES, Décio. A formação do Estado burguês no Brasil. Rio de Janeiro: Paz e terra, 1985.

A questão da autonomia relativa do Estado em Poulantzas. In: Crítica Marxista, n. 7. Xamã: São Paulo, 1998.

Trabalho recebido e aprovado em setembro de 2014. 